\title{
America Peruana e Oceanus Peruvianus: uma outra cartografia para o Novo Mundo ${ }^{I}$
}

\author{
Andréa Doré[1]
}

\begin{abstract}
Resumo
De 1550 até as primeiras décadas do século XVIII, as notícias sobre o império Inca e as riquezas minerais da porção ocidental da América do Sul influenciaram em vários aspectos a produção cartográfica sobre o continente. Este artigo analisa uma série de mapas produzidos a partir dos anos 1590, especialmente por alguns cartógrafos holandeses e portugueses, nos quais a centralidade do Peru se manifesta de formas diferentes, visando diversos objetivos. Entre essas formas, estão a nomeação do continente e do oceano Pacífico e o destaque dado à montanha de Potosi. Propõe-se, ainda, a inserção da expedição comandada pelo pirata inglês Bartholomew Sharp pela costa ocidental da América do Sul nos anos 1680 como um caso de circulação de mapas e de notícias das riquezas exploradas pelos espanhóis nesse período, bem como sua repercussão na cartografia. Palavras-chave: cartografia portuguesa; Potosi; cartografia da América do Sul.
\end{abstract}

\section{América Peruana y Oceanus peruvianus: una otra cartografía para el Nuevo Mundo}

\section{Resumen}

Desde 1550 hasta las primeras décadas del sigloXVIII, las noticias sobre el imperio incay las riquezas minerales de la parte occidental de América del Sur en muchos aspectos influyeron en la producción cartográfica sobre el continente. En este artículo se analiza una serie de mapas creados desde los años 1590, especialmente por algunos cartógrafos holandeses y portugueses, en los cuales la centralidad de Perú se manifiesta de diferentes formas, apuntando a diferentes objetivos. Entre ellas, está el nombramiento del continente y del océano Pacífico y el énfasis a la montaña de Potosí. También se propone la inserción de la expedición comandada por el piratainglés Bartholomew Sharp a lo largo dela costa occidental de América del Sur en los años 1680 como un caso de circulación de los mapas y de las noticias sobre las riquezas explotadas por los españoles en ese periodo, así como su impacto en la cartografía. Palabras clave: cartografía portuguesa; Potosí; cartografía de América del Sur.

\section{America Peruana and Oceanus Peruvianus: a different cartography of the New World}

\begin{abstract}
From 1550 to the first decades of the $18^{\text {th }}$ century, the news about the Inca Empire and the mineral wealth of the western portion of South America influenced the cartographic production about the continent in many ways. This article analyzes a series of maps produced from the 1590s onwards, especially by some Dutch and Portuguese cartographers, in which the centrality of Peru manifests in different forms and has different purposes. Among these forms are the naming of the continent and of the Pacific Ocean, and the emphasis placed on the Potosi mountain. We also propose the inclusion of the expedition commanded by the English pirate Bartholomew Sharp along the western coast of South America in the 1680s as a case of dissemination of maps and of news on the riches explored by the Spaniards during this period, as well as its impact on cartography.
\end{abstract}

Keywords: Portuguese cartography; Potosi; cartography of South America.

\section{Amérique Peruviénne et Oceanus Peruvianus: autre cartographie pour le nouveau monde}

\section{Résumé}

De 1550 à les premières decennies du XVIIIème siècle, les nouvelles concernant lempire Inca et les richeses minerales, à la partie occidentale del'Amérique duSud, ont influencé différents aspects dela production cartographique du continent.Cet article examine un certain nombre de cartes produits depuis 1590, particulièrement par cartographes hollandais et portugais, oùle centre du Perou se manifeste sous différentes formes, envue datteindre plusieurs objectifs. Entre ces formes, on souligne la nomination du continent et de l'océan Pacifique, et lévidence mis sur la montagne Potosi. En outre, linsertion de lexpédition commandée par le pirate anglaise Bartholomew Sharple long de la côte occidentale del'Amérique duSud est proposé comme un cas de circulation de cartes et nouvelles sur les richesses expliotées par les espagnols pendant cette période, ainsi que sa répercussion dans la cartographie. Mots-clés: cartographie portugaise; Potosi; cartographie de l'Amérique du Sud.

Artigo recebido em 03 de feveiro de 2014 e aprovado para publicação em 03 de maio de 2014

[1] Universidade Federal do Paraná (UFPR) - Curitiba (PR) - Brasil. E-mail: andreadore@ufpr.br

'Este trabalho resulta de pesquisa realizada durante estágio de pós-doutorado na Universidade de Harvard, financiado pelo Conselho Nacional de Desenvolvimento Científico e Tecnológico (CNPq), 2012-2013, e por uma bolsa de pesquisa concedida pela John Carter Brown Library, da Brown University, em 2013. Uma versão inicial deste texto foi apresentada no Congresso Internacional El Pacifico, 1513-2013. De la Mar del Sur a la construcción de un nuevo escenario oceánico, realizado em Sevilha, entre 23 e 27 de setembro de 2013. 
leitura de cosmografias e relatos de viagem produzidos entre 1550 e 1700 indicam que o vice-reino do Peru era, para os europeus, a porção mais importante da América do Sul, mesmo com delimitação nebulosa e instável. As riquezas dos incas e os metais preciosos que os espanhóis exploravam nas montanhas do Peru ocupavam papel central nas descrições do continente, juntamente com as repetidas referências ao canibalismo no norte do continente e no litoral atlântico da "Terra do Brasil"; as menções menos frequentes aos patagones, gigantes da região sul; as citações às amazonas que ficavam às margens do grande rio Maranhão, Amazonas ou Orellana — sendo usadas e confundidas as três denominações.

Esses dois gêneros da literatura geográfica - cosmografias e crônicas de viajantes -, como definiu Geoffroy Atkinson, ${ }^{2}$ fundiram-se na produção cartográfica, na qual a ênfase na região noroeste da América do Sul não desapareceu, mas adquiriu outras expressões. Minha proposta neste artigo é chamar atenção para as motivações e os desdobramentos da nomeação do Novo Mundo, das terras e dos mares, realizado pelo cartógrafo holandês Petrus Plancius: a America Peruana estende seu nome ao Oceanus Peruvianus. Seguindo-se essas designações e suas derivações, pretende-se acessar a produção do conhecimento geográfico europeu a respeito do continente, desenvolvido a partir dos anos 1590. Simultaneamente, a cartografia portuguesa, inserida no contexto da União Ibérica, representou o protagonismo das minas do Peru de forma bastante peculiar, indicando a projeção de determinadas expectativas sobre o continente. Além da análise desses mapas, proponho o estudo de um aspecto da expedição corsária de Bartholomew Sharp como um caso de circulação dessas representações cartográficas.

\section{Peruana: uma outra denominação da América}

A década de 1590 marca um importante momento da representação cartográfica da América do Sul, levando-se em conta a hierarquização dos espaços definida pelo cartógrafo. Em 1592, por obra do teólogo, cartógrafo e astrônomo holandês Petrus Plancius, a América do Sul é denominada, ao que tudo indica, pela primeira vez, Peruviana, e a província do Peru, ou vice-reino, Peruana. ${ }^{3}$

A importância do Peru na nomeação do continente já era observada nas décadas anteriores, nos mapas de Pedro de Medina, de 1550, de Francisco López

\footnotetext{
${ }^{2}$ Ver Geoffroy Atkinson, Les nouveaux horizons de la Renaissance Française, Paris, Droz, 1935, p. xiv-xv. Para Ricardo Padrón, no contexto das explorações marítimas, verifica-se a produção de uma literatura cartográfica, que pode ser iconográfica ou discursiva, "which built its empire at a time when it was only first learning how to picture the world" (que construiu seu império em um momento em que apenas se começava a aprender como retratar o mundo). Ver Ricardo Padrón, The Spacious Word. Cartography, Literature, and Empire in Early Modern Spain, Chicago; London, The University of Chicago Press, 2004, p. 12.

${ }^{\vee}$ Ver Marcel Destombes, La Mappemonde de Petrus Plancius, gravée par Josua van den Ende 1604, d'après lunique exemplaire de la Bibliothèque Nationale de Paris, Indo-Chine, Publications de la Société de Geographie de Hanoi, 1944, p. 2.
} 
de Gómara, de 1552, ou nos títulos dos mapas de Paolo di Forlani, de 1564, La Descrittione di tutto il Peru, e de Gerard de Jode, de 1578, Americae Peruvi... ${ }^{4}$

Plancius realizou no mesmo período mapas de maior circulação e que influenciaram produções seguintes. Em seu mapa-múndi de 1594 sobre a América do Sul, figura o nome America Peruana e, às margens, a alegoria do continente Peruana sintetiza diferentes informações sobre o Novo Mundo: o canibalismo, os animais exóticos e o ouro. O Novo Mundo é dividido em América Mexicana e América Peruana. Plancius insere ainda outra novidade: o Oceano Pacífico, ou Mar do Sul, é referido como Oceanus Peruvianus. ${ }^{5}$

Entre 1592 e 1594, foram impressos por Cornelis Claesz, em Amsterdam, mapas da América do Sul dividida em duas partes, também de autoria de Plancius. Em um mapa, está representada a parte sul da América do Sul e a Magelanica, continente que se acreditava existir ao sul da Terra do Fogo. Ao lado deste, foi inserido outro mapa, em que figura praticamente toda a América do Sul, com exceção do extremo norte, intitulado Haec pars Peruvianae... ${ }^{6}$

$$
\begin{gathered}
\text { O Novo Mundo é dividido em América Mexicana } \\
\text { e América Peruana. Plancius insere ainda outra } \\
\text { novidade: o Oceano Pacífico, ou Mar do Sul,é } \\
\text { referido como Oceanus Peruvianus }
\end{gathered}
$$

A denominação da terra e do oceano a partir do Peru encontrou vários seguidores. Em 1596, Theodore de Bry incluiu um mapa com essa nomenclatura em sua obra Grands Voyages ${ }^{7}$ e Arnold e Henricus Florent van Langren também a adotaram em seu mapa. ${ }^{8}$ No mesmo ano, o trabalho de Plancius

\footnotetext{
${ }^{4} \mathrm{O}$ mapa de Pedro de Medina está em sua Suma cosmográfica. Ver Mariano Cuesta Domingo, La obra cosmográfica y náutica de Pedro de Medina, Madrid, BCH, 1998; A navigator's Universe - The Libro de Cosmographía of 1538 by Pedro de Medina, Translated and with an Introduction by Ursula Lamb, Chicago, The University of Chicago Press, 1972; David C. Goodman, Power and penury: government, technology and science in Philip Il's Spain, Cambridge; New York, Cambridge University Press, 1988, p. 50-87. O mapa de López de Gómara foi inserido na primeira edição: Istoria de Indias y conquista de Mexico, Çaragoça, en casa de Agustin Millan, 1552. Acervo da John Carter Brown Library (JCBL), Providence, Estados Unidos. Disponível em: <http://tinyurl. com/q5exph9>. Acesso em: 14 de maio de 2014. Ver Cristián A. Roa-de-la-Carrera, Histories of Infamy. Francisco López de Gómara and the Ethics of Spanish Imperialism, Colorado, University of Colorado Press, 2005, p. 77 et seq.; Ricardo Padrón, The Spacious Word. Cartography, Literature, and Empire in Early Modern Spain, Chicago; London, The University of Chicago Press, 2004, p. 137 et seq. Sobre Forlani, ver David Woodward, "Paolo Forlani: Compiler, Engraver, Printer, or Publisher?", Imago Mundi, vol. 44, 1992, p. 45-64. Sobre Gerard de Jode, ver Fern Van Ortroy, L'Oeuvre Cartographique de Gérard e de Corneille de Jode, Amsterdam, Meridian Pub. Co., 1963 [1914]. ${ }_{5}^{5}$ Petrus Plancius; Joannes van Doetecum II, Orbis terrarum typus de integro multis in locis emendatus. [London], [Christopher Barker, George Bishop and Ralph Newberie], 1594. JCBL. Disponível em: <http://tinyurl. com/kck3rt5>. Acesso em: 14 de maio de 2014.

${ }^{6}$ Petrus Plancius, Haec pars Peruvianae, regiones Chicam \& Chile[nsem] complectitur, \& Regionem Patagonum, Amsterdam, [Cornelis Claesz], [1592-1594]. JCBL. Disponível em: <http://tinyurl.com/nvf9dpc>. Acesso em: 14 de maio de 2014.

${ }^{7}$ Mapa America sive Novus orbis respectu Europaeorum inferior globi terrestris pars, Frankfurt, 1596. JCBL. Disponível em: <http://tinyurl.com/pk8ambw>. Acesso em: 14 de maio de 2014.

${ }^{8}$ Arnold Florent van Langren; Henricus F. ab (Henricus Florentius) Langren, Orbis terrae compendiosa descriptio ex peritissimorum totius orbis Gaeographorum operibus desumta, [Antwerp], Joañem Baptistam Vrient, [1596]. JCBL. Disponível em: <http://tinyurl.com/paxevvh>. Acesso em: 14 de maio de 2014.
} 


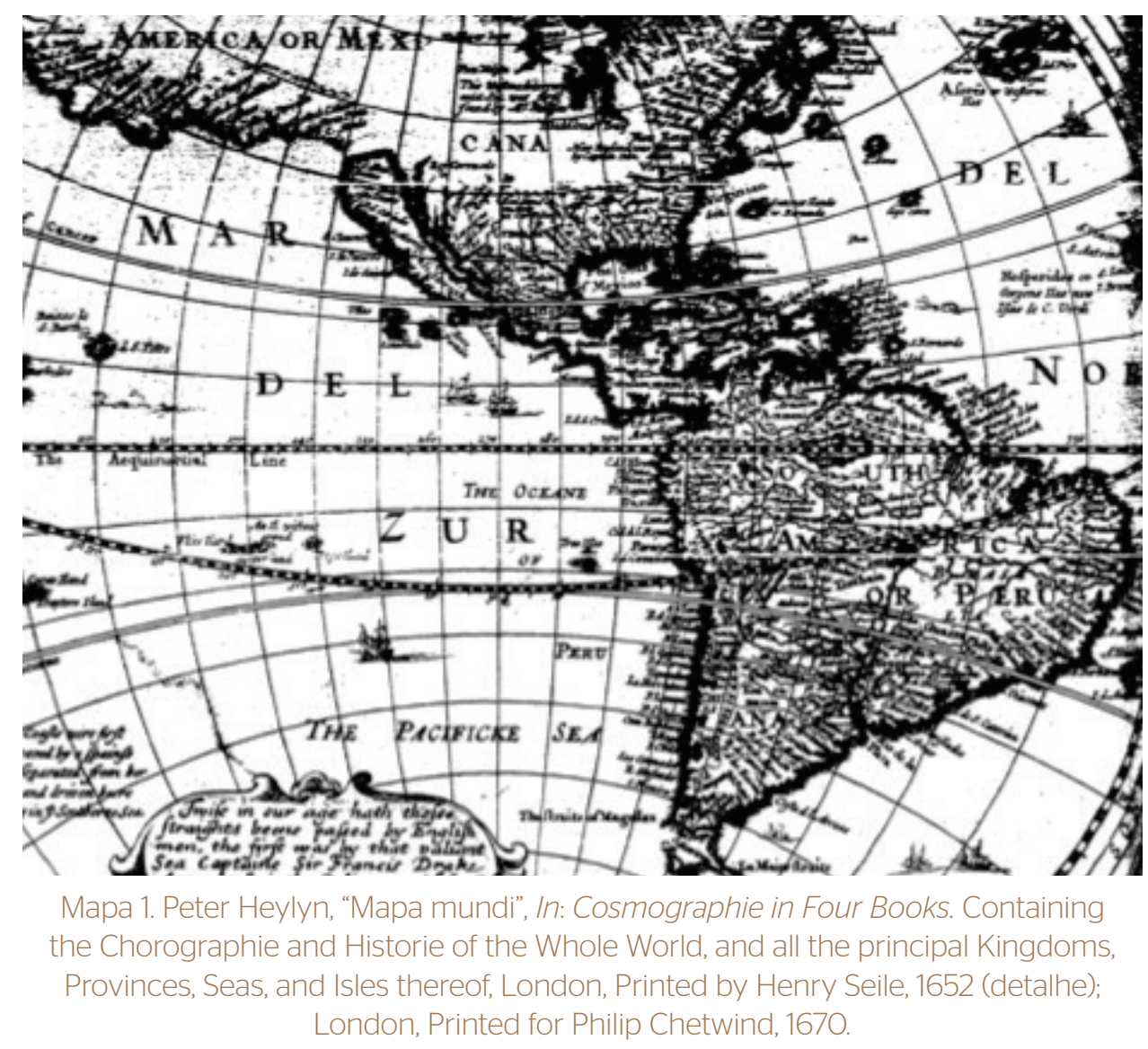

deu origem a cinco mapas inseridos em uma obra de grande importância para a empresa ultramarina holandesa. Jan Huygen van Linschoten, depois de viver cinco anos em Goa, entre 1583 e 1588, a serviço do arcebispo na capital do Estado da Índia, voltou à Europa com informações sobre o tráfico das especiarias, as rotas utilizadas pelos portugueses e a vida cotidiana no mais importante enclave português na Ásia. Levou ainda roteiros de navegação portugueses que só sobreviveram graças à sua publicação. Seu Itinerario, publicado em Amsterdam, continha mapas muito provavelmente de sua autoria com planos de Goa, Moçambique e Angra, nos Açores. ${ }^{9}$ A primeira edição do seu Itinerario foi acompanhada de um texto dedicado à descrição da América e mapas gravados por Henricus Florentinus van Langren. ${ }^{10}$

A America Peruana chegou à Inglaterra com a obra de Peter Heylyn (Mapa 1), teólogo e historiador, autor de Cosmographie in Four Books, que teve várias

\footnotetext{
9Para o mapa baseado em Plancius, ver Jan Huygen van Linschoten, Histoire de la Navigation de IEAN HVGVES de Linschot Hollandois, aux Indes Orientales, Amsterdam, lean Evertsz Cloppenburch, 1619. Para uma edição moderna e em português desse texto, ver Itinerário, Viagem ou Navegação de Jan Huygen van Linschoten para as Indias Orientais ou Portuguesas. Edição de Arie Pos e Rui Manuel Loureiro, Lisboa, CNCDP, 1997. Ver Cornelis Koeman, "Jan Huygen van Linschoten", Separata da Revista da Universidade de Coimbra, Centro de Estudos de História e de Cartografia antiga, vol. XXXII, p. 27-40, 1985. (Série Separatas 153). ${ }^{10}$ Ver Armando Cortesão; Avelino Teixeira da Mota, Portugaliae Monumenta Cartographica (PMC), Lisboa, Comissão Executiva das Comemorações do V Centenário da Morte do Infante D. Henrique, 1987, vol. 4, p. 99-100, 6 v.
} 
edições e reimpressões ao longo do século XVII. Na edição de 1652, a América do Sul é chamada Peruana America e a edição de 1670 contém um mapamúndi no qual sobre a massa do continente figura South America or Peruana. Nas águas do oceano, verifica-se a justaposição de nomes, com os tipos gráficos indicando uma hierarquia, do mais amplo e abrangente MAR DEL ZUR ao mais restrito às costas do vice-reino, The Oceane of Peru, passando pelo The Pacificke Sea, mais próximo do sul da América do Sul. ${ }^{11}$

Os mapas de Petrus Plancius, segundo demonstrou Armando Cortesão por meio da análise da nomenclatura empregada, foram realizados a partir de mapas feitos pelo cartógrafo português Bartolomeu Lasso. Há poucas notícias sobre esse cartógrafo. Sabe-se que recebeu autorização régia "para fazer cartas de marear e estrellabios e agulhas" e foi examinado pelo matemático Pero Nunes, cosmógrafo-mor, e também por Jorge Reinel, outro importante cartógrafo. De autoria de Lasso são conhecidos um atlas - assinado e datado de 1590, contendo oito cartas - e três cartas não datadas. ${ }^{12}$

A passagem dos mapas do atelier de Lasso para as mãos de Petrus Plancius traz à cena a circulação de informações sobre as novas rotas marítimas e terras ainda não mapeadas pelos europeus, assim como a circulação de mapas e de indivíduos entre monarquias, governos e casas comerciais em um momento de grande desconfiança, concorrência e imprecisão geográfica. Mesmo que a espionagem e o contrabando de informações não sejam objeto de análise deste artigo, alguns comentários podem auxiliar na compreensão dos mapas aqui selecionados.

Entre os europeus, ninguém conhecia melhor as terras do Novo Mundo e as rotas para atingi-las do que os ibéricos, porém isso não significa que tal conhecimento havia sido adquirido ou era dominado apenas por portugueses e espanhóis. Muitos estrangeiros, sobretudo italianos, foram decisivos para as viagens de expansão, como os casos emblemáticos de Cristóvão Colombo, Américo Vespúcio e Sebastião Caboto. As monarquias ibéricas, por meio de seus oficiais e instituições, tentaram controlar a divulgação de informações geográficas que pudessem municiar iniciativas concorrentes. No caso dos mapas, o problema do segredo sobre as cartas se dividia entre a necessidade de conhecer as rotas marítimas através do Atlântico, para garantir a circulação das naus espanholas, e o uso de mapas para legitimar reivindicações territoriais e isso exigia que se tornassem públicos. Surgem, assim, dois diferentes

\footnotetext{
"Ver Peter Heylyn, Cosmographie in Four Books. Containing the Chorographie and Historie of the Whole World, and all the principal Kingdoms, Provinces, Seas, and Isles thereof, London, Printed by Henry Seile, 1652; Printed for Philip Chetwind, 1670.

${ }^{12}$ Armando Cortesão explica que Wieder, em sua Monumenta Cartographica, vol. 2 (p. 27-46), afirma a influência da obra de Lasso nos mapas de Petrus Plancius e lembra que, antes dele, P.A. Tiele, E. W. Dahlgren e P. Teleki tinham demostrado que Plancius utilizara um trabalho de Lasso para a feitura do seu Planisfério. Ver Armando Cortesão, Cartografia e cartógrafos portugueses dos séculos XV e XVI, vol. 2, Lisboa, Seara Nova, 1935, p. 285-287 e PMC, vol. 3, p. 91-97.
} 
tipos de conhecimento sobre os espaços explorados, um liderado pelos cosmógrafos e outro pelos pilotos, conforme identificou Alison Sandman. ${ }^{13}$

Os cosmógrafos, especialmente no seu papel de produtores de mapas, tinham o foco na informação sobre a localização dos lugares, distâncias, tamanhos e formas, dados que, originalmente, precisavam ser obtidos no local e exigiam alguma habilidade cosmográfica para que pudessem ser dispostos em um mapa. Os pilotos, por sua vez, estavam preocupados em como ir de um lugar a outro, o que demandava não apenas dados sobre distâncias, potencialmente longitudes e latitudes, mas também detalhes sobre ventos, correntes marítimas e entradas de portos. Esse conhecimento detalhado dos espaços navegados só podia ser apreendido por meio de longa experiência no mar.

Os oficiais encarregados de manter secretas determinadas informações resultantes das explorações marítimas desenvolveram diferentes estratégias para os dois tipos de conhecimento. Como os aspectos valorizados pelos cosmógrafos - vinculados ao conhecimento teórico e sistemático - eram mais úteis para a diplomacia e menos úteis para a navegação, foram simultaneamente enfatizados e publicizados e as tentativas de controle estavam, assim, mais ligadas a uma disseminação cuidadosa do que propriamente ao segredo. Ao mesmo tempo, o conhecimento experimental dos pilotos, fosse ele dominado pelo indivíduo ou disposto em mapas e roteiros, deveria permanecer secreto. ${ }^{14}$

\section{O problema do segredo sobre as cartas se dividia entre a necessidade de conhecer as rotas maritimas através do Atlântico, para garantir a circulação das naus espanholas, e o uso de mapas para legitimar reivindicações territoriais}

A negociação dos mapas feita por Bartolomeu Lasso demonstra que o controle da Coroa espanhola e de seus oficiais não conseguiu manter as informações gerais fora do alcance de várias potências europeias, concorrentes de Portugal e Espanha. Tentando burlar o controle ibérico, estava o trabalho de espiões, mercadores e, igualmente, de humanistas interessados em informações atualizadas sobre os territórios explorados. Esses agentes, exercendo muitas vezes e ao mesmo tempo diferentes funções, estiveram na origem da transação dos mapas. Em 1592, Petrus Plancius teria aconselhado seus sócios em Amsterdam

\footnotetext{
${ }^{13}$ Ver Alison Sandman, "Controlling knowledge. Navigation, cartography, and secrecy in the Early Modern Spanish Atlantic", In: James Delbourgo; Nicholas Dew (eds.), Science and empire in the Atlantic World, New York; London, Routledge, 2008, p. 31-33. Sobre o controle exercido pela Casa de Contratación, ver também María M. Portuondo, Secret science: Spanish cosmography and the New World, Chicago, University of Chicago Press, 2009, p. 103-105. Sobre uma suposta política do sigilo defendida pelos portugueses a respeito das descobertas marítimas, ver Luís de Albuquerque, Dúvidas e certezas na história dos descobrimentos portugueses, Lisboa, Vega, 1991, p. 57-65. ${ }^{14}$ Ver Alison Sandman, op cit., p. 33.
} 


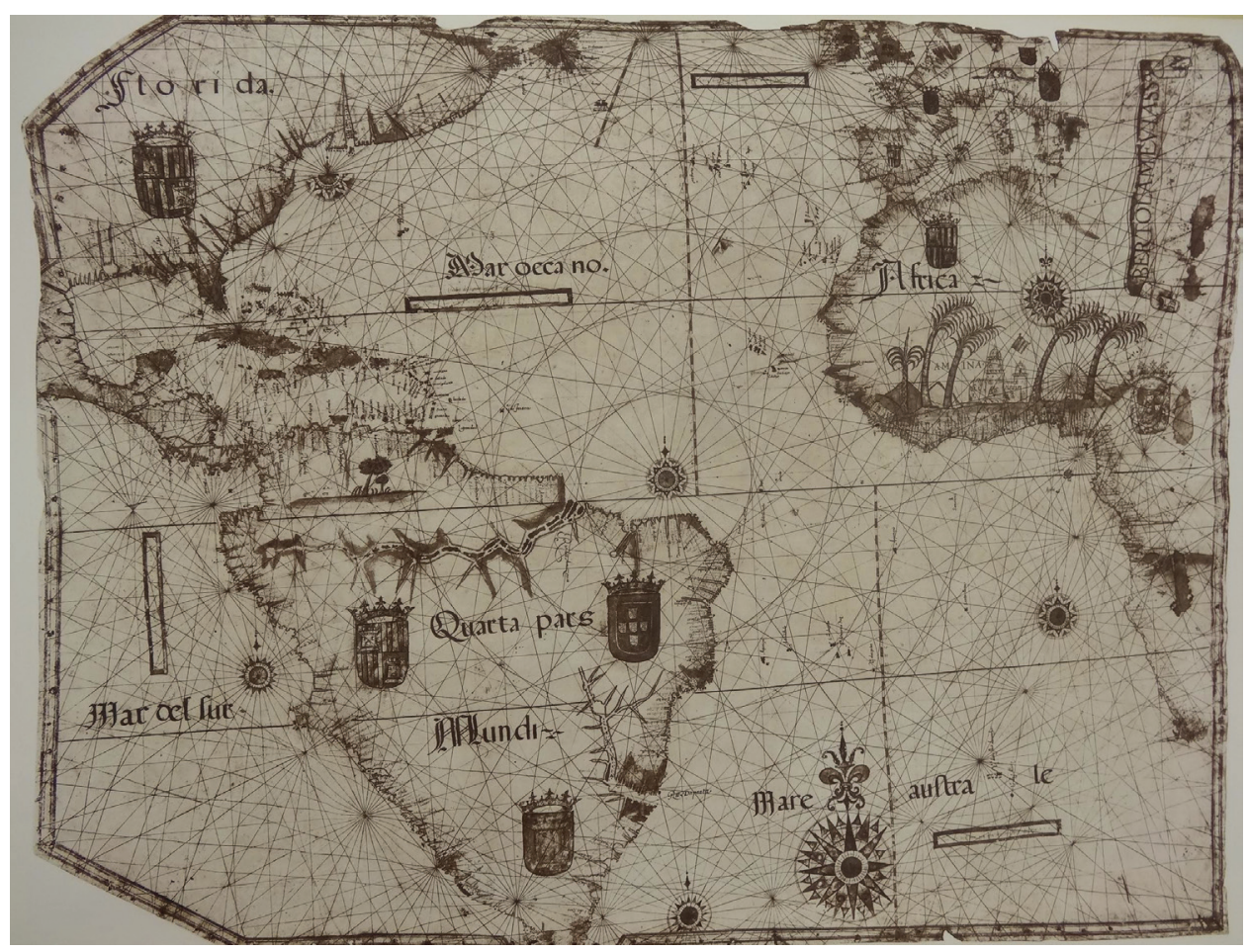

Mapa 2. Bartolomeu Lasso, c. 1586. Lord Salisbury’s Library, Hatfield, Hertford. Portugaliae Monumenta Cartographica (PMC), vol. 3. Estampa 378.

a espionar os pilotos portugueses de Lisboa. A partir das memórias de Plancius, Koeman afirma que os mapas foram adquiridos pelos irmãos Cornelis e Frederik de Houtman, que, no início dos anos 1590, foram a Lisboa para esse fim. ${ }^{15}$

Os mapas de Bartolomeu Lasso, no entanto, não trazem a nomenclatura Peruana, seja na massa de terra, seja no oceano (Mapa 2). Lasso prefere as denominações Quarta pars Mundi e Mar del Sur. Além de um grande número de topônimos ao longo de toda a costa, o mapa contém uma pequena ilustração com algumas árvores no extremo norte da América do Sul e as representações das bacias do "Rio da Prata" e do "Rio das Amazonas". Em plena união das coroas ibéricas sob o poder Habsburgo, o cartógrafo inseriu o brasão da monarquia portuguesa a oeste e dois brasões da monarquia espanhola na parte leste e ao sul.

Se Plancius se baseou no mapa português para o contorno da costa e a adoção de muitos topônimos, a atribuição do nome America Peruana ao continente, por sua vez, resultou de uma interpretação original e inédita das características do Novo Mundo. Mas por que o cartógrafo holandês optou

\footnotetext{
${ }^{15}$ Além da semelhança entre os mapas de Lasso e Plancius, outra evidência revelaria a sua fonte. Ao solicitar o privilégio para a publicação do mapa-múndi de Plancius de 1592, Cornelis Claesz também pediu o privilégio para "to draw or print the 25 special charts obtained from Bartholomeo de Lasso, cosmographer and practitioner of navigation of the king of Spain, through the good offices of Mr. Petrus Plancius, but paid by himself' (desenhar ou imprimir os 25 mapas especiais obtidos de Bartholomeo de Lasso, cosmógrafo e prático da navegação do rei da Espanha, por meio dos bons serviços do Sr. Petrus Plancius, mas pago por ele mesmo). Cornelis Koeman, "Jan Huygen van Linschoten", Separata da Revista da Universidade de Coimbra, Centro de Estudos de História e de Cartografia antiga, vol. XXXII, 1985, p. 27-4O. (Série Separatas 153).
} 
por qualificar o continente e não utilizar apenas o nome Peru ou a denominação America Meridionalis? Em 1558, Gerard Mercator já havia produzido um mapa em que, pela primeira vez, o nome América é utilizado para o continente especificando sua divisão: America pars meridionalis e America pars septentrionalis. ${ }^{16}$ Numerosos e importantes cartógrafos holandeses mantiveram essa nomenclatura, como Abraham Ortelius, Hendrix e Jodocus Hondius e Joan Blaeu, fixando, inclusive o nome "Pacífico" ou "Mar do Sul" para o grande oceano a ocidente do Novo Mundo, como bem expressa o mapa de Ortelius, de 1589, intitulado Maris Pacifici (quod vulto Mar del Zur). ${ }^{17}$

\section{O domínio sobre o conhecimento do Novo Mundo}

A visualização de um considerável número de mapas produzidos nos séculos XVI e XVII permite concluir que as duas formas de nomear o continente - America Peruana e America Meridional — não são excludentes, mas se baseiam em critérios distintos. America Meridional surge de indiscutíveis e precisas observações geográficas sobre a disposição da massa continental no globo terrestre. Apesar de ter como referência a divisão da terra em dois hemisférios, os autores explicam que não é a linha Equinocial — ou seja, a linha do Equador — que divide as duas massas de terra, mas o estreito de Darien, do Panamá, passagem de terra mais estreita antes de se chegar à América do Sul, fronteira atual entre a Colômbia e o Panamá. Em 1690, o autor anônimo de uma obra chamada Les Principes de la Geographie explicava que a América "é naturalmente dividida pelo istmo do Panamá, \& não pelo equador em Setentrional ou Mexicana, \& em Meridional, ou Peruviana". E acrescentava: "O Peru é a parte mais importante da América Meridional, que recebe o nome de Peruviana" ${ }^{18} \mathrm{~A}$ nomeação do continente feito por Petrus Plancius caracteriza, assim, uma nova abordagem. Sua nomenclatura pretendia qualificar o espaço, adjetivá-lo, visava sintetizar informações históricas e dados científicos. A denominação America Peruana classifica a região como já visitada, conhecida e explorada pelos europeus. Esse nome remete à interferência e à presença dos europeus, à experiência advinda da exploração e da conquista de um novo continente, relatada e registrada por diferentes autores.

Uma interpretação para a escolha de Petrus Plancius poderia levar em conta que, durante a União Ibérica, essa denominação obteve grande repercussão, conferindo uma conotação política à decisão do cartógrafo. Uma vez que toda

\footnotetext{
${ }^{16}$ Ver Isa Adonias (org.), "Um continente chamado América”, Mapa. Imagens da Formação Territorial Brasileira, Rio de Janeiro, Fundação Emílio Odebrecht, 1993, p. 27.

${ }^{17}$ Ver Paulo Miceli (org.), O tesouro dos mapas: a cartografia na formação do Brasil, São Paulo, Instituto Cultural Banco Santos, 2002, p. 88.

${ }^{18}$ A América "est naturellement divisée par listhme de Panama, \& nom par l'équateur en Septentrionale ou Mexicaine, \& en Meridionale, ou Peruvianne" (p. 206 - grifos da autora). E o autor anônimo acrescentava: "Le Perou est la plus considerable partie de l'Amerique Meridionale, qui en prend le nom de Peruviane" (p. 208). In: Les Principes de la Geographie Methodiquement expliquez, Pour donner une Idée generale de toutes les parties de l'Univers, \& pour faciliter l'intelligence des Tables \& des Cartes Geographiques. Avec un Abregé Chronologique, Pour servir d'Introduction à l'Etude de l'Histoire, Amsterdam, Chez Abraham Wolfgang, Près de la Bourse, 1692
} 
a América do Sul estava sob o domínio de Filipe II, seria adequado nomear todo o continente a partir do vice-reino espanhol. No entanto, não é tão fácil identificar uma forte relação entre a tradição do nome America Peruana e a união das coroas ibéricas. Plancius foi, pessoalmente, bastante prejudicado pelo poder crescente de Filipe II. Quando vivia em Bruxelas, em março de 1585, Alexandre Farnese, comandante do exército de Flandres, tomou a cidade e Plancius foi obrigado a fugir, disfarçado de soldado espanhol, como conta em suas memórias. Ele participou ainda da fundação da Companhia Holandesa das Índias Orientais (VOC), a ameaça mais poderosa às possessões ibéricas na Ásia. ${ }^{19}$ Essas contingências políticas e econômicas enfraquecem a hipótese de que um poder político unificado pelos Habsburgo estaria na origem da denominação dada ao continente e ao oceano adjacente pelo cartógrafo holandês.

Minha interpretação da escolha de Plancius se insere no contexto em que atuaram cartógrafos e cosmógrafos. Como Plancius, muitos humanistas nos séculos XVI e XVII atribuíram a si a tarefa de descrever e explicar o mundo e, para isso, dispunham basicamente de três diferentes tradições herdadas da Antiguidade: uma científica, uma literária e uma prática. A tradição científica ou matemática, baseada em Ptolomeu, contribuiu para a representação das terras em mapas. Outra tradição, mais literária, histórica e descritiva, pintou o homem e suas ações sobre a superfície da terra, como fez Estrabão. E uma terceira tradição, herdada do pensamento prático de Aristóteles e dos filósofos estoicos, estudou o mundo de acordo com os quatro estados, ou elementos, da matéria: terra, água, fogo e ar. ${ }^{20}$

Os cosmógrafos buscaram, de forma incongruente a nossos olhos, unir o conhecimento clássico, a partir dessas diferentes tradições, às novas descobertas geográficas. Um exemplo desse esforço de conciliação são os debates sobre a formação dos metais. A busca de uma explicação para a origem dos metais gerava desde a Antiguidade um bom número de teorias que, em situações diversas, foram usadas para fundamentar a procura efetiva de minas. Giuseppe Rosaccio, em seu Teatro del Mondo, de 1595, explicava, baseado na literatura clássica, que os metais eram gerados "nas vísceras da Terra" e eram atribuídos aos sete planetas: o ouro era atribuído ao Sol; a prata, à Lua; o ferro, a Marte; o Mercúrio ("l'argento vivo"), a Mercúrio; o estanho, a Júpiter; o cobre, a Vênus; e o chumbo, a Saturno. ${ }^{21}$

A partir de Aristóteles e de sua obra Metereologicas, afirmava-se que os metais eram feitos principalmente de vapores e exalações produzidas no centro da terra. ${ }^{22}$ Aristóteles também admitia, como influência celeste, que o calor do sol

\footnotetext{
19 Ver Marcel Destombes, La Mappemonde de Petrus Plancius, gravée par Josua van den Ende 1604, d'après l'unique exemplaire de la Bibliothèque Nationale de Paris, Indo-Chine, Publications de la Société de Geographie de Hanoi, 1944, p. 4-5.

${ }^{20}$ Ver François de Dainville, La géographie des humanistes, Paris, Beauchesne et ses fils, 1940, p. 75.

${ }^{21}$ Giuseppe Rosaccio, Teatro del Mondo e sue parti cioe Europa, Affrica, Asia, ed America, Nel quale, oltre alle Tavole in disegno, si discorre delle sue Provincie, Regni, Regioni, Città, Castelli, Ville, Monti, Fiumi, Laghi, Mari, Porti, Golfi, Isole, Popolazioni, Leggi, Riti, e Costumi. Da Giuseppe Rosaccio com brevità descritto, Bologna, Constantino Pisarri, 1724 [1595]. Cap. VI - Delle Generazione de’ Metalli, e sue cause.

${ }^{22}$ Ver D.E. Eichholz, "Aristotle's Theory of the Formation of Metals and Minerals", The Classical Quarterly, vol.. 43, n. 3-4, 1949, p. 141.
} 
promovia a mistura de exalações, da qual os minerais eram engendrados. Como consequência dessa teoria, a zona tórrida seria a mais propícia para a geração de metais. No século XVI, ela teve muito prestígio e fez supor a existência de uma região que guardava grandes riquezas e estaria situada nas proximidades da Linha Equinocial, no interior do continente sul-americano. Os Reis Católicos Fernando e Isabel, logo após o retorno da primeira viagem de Colombo, se referiram a essa teoria em uma carta ao explorador, na qual consultavam sobre a conveniência de alterar a bula papal para ser incluída uma maior extensão de terra dessa franja da linha do Equador nos domínios de Castela. Os Reis tinham recebido informações de alguns portugueses, os quais afirmavam ser possível encontrar, na zona tropical, ilhas e terras que "de acordo com a parte do sol em que estão, acreditase que serão muito proveitosas e mais ricas do que todas as outras."23

\section{Os cosmógrafos buscaram, de forma incongruente a nossos olhos, unir o conhecimento clássico, a partir dessas diferentes tradições, às novas descobertas geográficas}

Vários autores de cosmografias e mapas, como Pierre d'Avity, Giovanni d'Anania e Giuseppe Rosaccio, iniciam seus trabalhos com uma lista de autores de relatos de viagem e cartas oriundos de explorações geográficas utilizados em suas descrições do mundo. Os textos de Francisco López de Gómara, José de Acosta e Gonzalo Fernandes de Oviedo foram frequentemente fontes para descrever a porção ocidental e os relatos de André Thevet, Jean de Lery e Hans Staden serviram de fonte sobre os canibais do Brasil. ${ }^{24}$

A decisão de Petrus Plancius pode ter se baseado em mapas anteriores, como os já citados, de Paolo di Forlani, La Descrittione di tutto il Peru, ou no de Gerard de Jode, America Peruvi. Pode ter sido igualmente influenciado

\footnotetext{
23 "según en la parte del sol que están se cree que serán muy provechosas y más ricas que todas las outras". Carta mensajera de los reyes al Alirante, 15 de Septiembre de 1493. Navarrete, Biblioteca de Autores Españoles, vol. I, p. 364, apud Beatriz Pastor; Sergio Callau (edición, introducción y notas), Lope de Aguirre y la rebelión de los marañones, Castalia, Madrid, 2011, p. 13.

${ }^{24}$ Cf. Lorenzo de Anania, La Universal Fabrica del Mondo, Napoli, Appresso Gioseppe Cacchii dell'Aquila, 1573; Pierre de Avity, Description generale de l'Amerique troisiesme partie du monde. Paris, Chez Claude Sonnius, 1637; Giuseppe Rosaccio, II mondo e sve parti cioe Europa, Affrica, Asia et America, Fiorenza, Apresso Francesco Tosi, 1595; André Thevet, Histoire d'André Thevet Angoumoisin, cosmographe du Roy, de deux voyages par luy faits aux Indes australes, et occidentales, Edition critique par Jean-Claude Laborie et Frank Lestringant, Genève, Droz, 2006; Jean de Léry, Histoire d'un voyage fait em le terra du Brésil, Édition, présentation et notes par Jean-Claude Morisot, Genève, Librarie Droz, 1975. Fac-símile da edição de 1580; Idem, Historia natural y moral de las Indias, Sevilla, Juan de León, 1590. Edição moderna: José de Acosta, Historia natural y moral de las Indias. Edición crítica de Fermín del Pino-Díaz, Madrid, Consejo Superior de Investigaciones Científicas, 2008. Ver também Frank Lestringant, O canibal. Grandeza e decadência, Brasília, Editora da UnB, 1997; Zinka Ziebell, Terra de canibais, Porto Alegre, Editora da Universidade Federal do Rio Grande do Sul, 2002; Shureka Davies, "Depictions of Brazilians on French Maps, 1542-1555", The Historical Journal, vol. 55, n. 2, June 2012, p. 317-348; e Yobenj Aucardo Chicangana-Bayona, "Canibais do Brasil: os açougues de Fries, Holbein e Münster (Século XVI)", Tempo, vol. 14, n. 28, 2009, p. 165-192.
} 
pelos trabalhos de Giacomo Gastaldi, importante cartógrafo do período, nos quais se baseou Giovanni Baptista Ramusio para o mapa que inseriu em sua coleção Navigationi e Viaggi. ${ }^{25}$ Para nutrir os mapas de Plancius, ainda estavam disponíveis os relatos de viagem, exaustivamente citados ou apropriados pelas cosmografias.

O objetivo principal do humanista Petrus Plancius e de outros como ele era descrever e nomear todo o mundo, seguindo métodos aceitos e respeitados por seus interlocutores, por seus pares, defendidos pela tradição clássica ptolomaica de produzir mapas e justificados pela experiência. Trata-se de um domínio que se exercia sobre o saber a respeito das novas terras. A nomeação, legitimada pela autoridade concedida a partir da tradição e da aura de imparcialidade inerente à ideia de ciência, então em construção, garantiria a tomada de posse. Nesse caso, não seria um mecanismo visando à posse política, mesmo que esta também tenha feito uso da nomeação como ritual obrigatório dos conquistadores, seguindo o que José Luís Romero identificou como o desígnio fundamental da conquista espanhola: "instaurar, sobre uma natureza vazia, uma nova Europa, a cujos montes, rios e províncias uma cédula real ordenava que se pusessem nomes, como se nunca tivessem tido". ${ }^{26}$

O domínio sobre o saber a respeito do Novo Mundo, por sua vez, estaria relacionado a uma ciência que definia, então, seus contornos. Segundo Klaus Vogel, no século XV, muitos dos cosmógrafos, criadores de mapas e globos e autores de tratados cosmográficos, tinham formação universitária, dominavam o latim - às vezes, também o grego - e muitos eram também teólogos. Já durante os séculos XVI e XVII, foi crescente o número de cosmógrafos oriundos das áreas da matemática, filosofia natural e da física. Passaram a ser mantidos não apenas pelas grandes cortes europeias, mas também por pequenas cortes, companhias de comércio, universidades e academias. Essa "ciência jovem e emergente,", dominada pelos cosmógrafos, mais tarde chamados de geógrafos, foi responsável pela construção de um conhecimento geográfico do Novo Mundo que instrumentalizou expedições e conquistas e, no caso da América da Sul, definiu vocações para determinadas regiões.

É difícil encontrar em tratados de geografia, produzidos e seguidos por esses cosmógrafos, orientações sobre a forma de nomear continentes, mares e oceanos.

\footnotetext{
${ }^{25}$ Ver Giovanni Baptista Ramusio, Terzo volume delle nauigationi et viaggi nel quale si contengono le nauigationi al Mondo Nuouo... In Venetia, nella stamperia de Giunti, L’anno M D LVI. [1556]. Giacomo Gastaldi foi um dos mais influentes cartógrafos do período, importante inclusive para a produção de Forlani. Ver Roberto Almagià, "Intorno ad un grande Mappamondo perduto di Giacomo Gastaldi (1561)", Bibliofilia, Estratto dal vol. XLI, Firenze, Leo S. Olschki Editore, 1939, p. 11-12 e Stefano Grande, Le Carte d'America di Giacomo Gastaldi. Contributto alla Storia della cartografia del secolo XVI, Torino, Carlo Clausen, 1905.

${ }^{26}$ “instaurar sobre una naturaleza vacía una nueva Europa, a cuyos montes, ríos y provincias ordenaba una real cédula que se les pusieran nombres como si nunca los hubieran tenido". José Luís Romero, Latinoamérica. Las ciudades y las ideas, 2. ed., Buenos Aires, Siglo XXI Editores, 2007, p. 12. Sobre os rituais de posse, ver também Stephen Greenblatt, Possessões maravilhosas: o deslumbramento do Novo Mundo, São Paulo, Edusp, 1996, p. 79-89 e Patrícia Seed, Cerimônias de posse na conquista europeia do Novo Mundo (1492-1640), São Paulo, Editora da Unesp, 1999.

27"young, emerging science". Ver Klaus A. Vogel, "Cosmography", In: Roy Porter; Katharine Park; Lorraine Daston (eds.), The Cambridge History of Science, III, Early Modern Science, Cambridge, Cambridge University Press, 2006, p. 471.
} 
Encontram-se, porém, nos textos cosmográficos do período, muitas discussões e interpretações a respeito do nome que deveriam receber as terras atingidas por Colombo e os sucessivos exploradores. O nome não foi consensual, cada um utilizando a nomenclatura que lhe parecia mais adequada e, muitas vezes, combinando diferentes opções. A de maior impacto foi, sem dúvida, a de Américo Vespúcio, Mundus novus, publicizada em carta escrita a Pietro Soderini, significando que não se tratava de uma parte da Ásia e não se deviam buscar ali características naturais, reinos e habitantes descritos por Marco Polo.

Depois da publicação de Mundus Novus, veio o que mais tarde se convencionou considerar o batismo cartográfico, com o texto de 1507, Cosmographiae Introductio, escrito pelo cosmógrafo alemão Martin Waldseemüller (1474-1518). Essa obra incluía, então, uma "Introdução à cosmografia”, as quatro navegações de Vespúcio e um mapa-múndi, com o nome America nele escrito pela primeira vez sobre uma imprecisa faixa de terra. Waldseemüller valeu-se de dois critérios para nomear o continente: a tradição advinda dos nomes dos outros continentes conhecidos e a homenagem ao feito daquele que ele julgava ser o descobridor. "Assim como a Europa e a Ásia receberam nomes femininos, eu não vi nenhuma razão que se pudesse justamente opor a que se chamasse esta parte América, ou seja, a terra de Amerigo, a partir de Amerigo, seu descobridor".28

Uma vez oferecida alguma explicação para a denominação das terras, os oceanos recebem um nome em referência às terras que banham sem mais comentários. O mesmo já acontecia em relação ao oceano que percorre a costa ocidental da África e que passou a dividir os dois continentes. Oceanus Aethiopicus, depois Mar do Norte e, finalmente, Oceano Atlântico, se referia a Aethiopia, ou Etiópia, forma como era denominada a África na Antiguidade.

"Oceano" era, na Antiguidade, o nome próprio do "rio que envolve toda a terra" e sobre o qual se observava com espanto um fluxo e refluxo de uma amplitude que não existia no Mediterrâneo. O “mar oceano", ou somente, o “oceano", permaneceu por muito tempo, para os geógrafos humanistas, o oposto do Mediterrâneo. Mesmo que os linguistas estivessem de acordo em associar a palavra oceano à ideia de imensidão, a cartografia, durante muito tempo, não pareceu segura sobre o seu uso. ${ }^{29}$ Daí também a indecisão que leva a tratar o oceano como Pacífico, Mar del Zur e Peruvianus.

Desde o mapa de Petrus Plancius, em 1594, passando pelo influente mapa-múndi de Blaeu, de 1608, até 1680, vários cartógrafos utilizaram a mais importante porção de terra da América do Sul para nomear o Oceano Pacífico, adotando diferentes grafias. Abraham Goos utiliza The Peruviane Ocean, em 1626. Nicolas Visscher e Pieter Goos usam Oceanvs Pervviensis, em 1650.

\footnotetext{
${ }^{28}$ Martin Waldseemüller; Miguel León Portilla; Amerigo Vespucci, Introducción a la Cosmografía y las Cuatro Navegaciones de Américo Vespucio, Traducción del latín, estudio introductorio y notas de Miguel LeónPortilla, México, Universidad Nacional Autónoma de México, 2007, p. 70. Ver também Eviatar Zerubavel, Terra Cognita. The mental Discovery of America, New Brunswick, Rutgers University Press, 1992, p. 80-81 e Isa Adonias (org.), Um continente chamado América. Mapa. Imagens da Formação Territorial Brasileira, Rio de Janeiro, Fundação Emílio Odebrecht, 1993, p. 26.

${ }^{29}$ Ver Dainville, Le Langage des Géographe. Terme. Signes, Coulerus des Cartes Anciennes 1500-1800, Paris, Éditions A. et J. Picard \& Cie., 1964, p. 100-101.
} 
Dankerts, em 1680, adota dois nomes em seu mapa: Oceanus Peruvanus e Mar $d u$ Peru. Nicolas Sanson, na edição francesa de 1650, escreve Mer du Perou e nomeia também outros mares, assim como na edição inglesa de 1680, Sea of Peru. ${ }^{30}$ Nesse contexto de indefinição nominativa e justaposição de critérios, a cartografia portuguesa se diferenciou com uma forma bastante particular de referenciar a importância do vice-reino do Peru. Sem batizar todo o continente ou o oceano e sem usar a nomenclatura inaugurada por Plancius e seus colaboradores, a referência geográfica e histórica mais espetacular nos mapas portugueses é a montanha de Potosi. Se, em algumas cosmografias e relatos de viagem, as riquezas do Peru poderiam estar associadas à captura do inca Atahualpa por Francisco Pizarro em Cajamarca e ao imenso tesouro reunido para o seu resgate, nos mapas portugueses, produzidos entre 1600 e 1688, encontra-se com inconfundível destaque a ilustração da montanha de prata, encimada quase sempre por uma cruz. ${ }^{31}$

"Oceano" era, na Antiguidade, o nome próprio
do "rio que envolve toda a terra" e sobre o qual se
observava com espanto um fluxo e refluxo de uma
amplitude que não existia no Mediterrâneo

Em um atlas anônimo, preservado em Turim e atribuído aos cartógrafos portugueses Luís Teixeira e João Baptista Lavanha, produzido entre 1596 e 1612, a alta montanha se destaca pela primeira vez quase no centro do continente, ainda sem a cruz (Mapa 3). Foi justamente a partir do atelier dos Teixeira, uma das mais produtivas famílias de cartógrafos portugueses, que essa imagem se desenvolveu e fez discípulos. A representação se repete com algumas alterações em mapas de diferentes cartógrafos: João Teixeira Albernaz I (em mapas

\footnotetext{
${ }^{30}$ Abraham Goos, America with those known parts in that unknowne worlde both people and manner of buildings described and inlarged by I.S. Ano 1626, London, [1631]. Disponível em: <http://tinyurl.com/ o4bdcww>. Acesso em: 14 de maio de 2014; Nicolaes Visscher (Claes Janszoon); Pieter Goos, Orbis terrarum typus de integro multis in locis emendatus, [Amsterdam], 1650. Disponível em: <http://tinyurl. com/ousw2ko>. Acesso em: 14 de maio de 2014; Dankerts, Novissima et Accuratissima Totius Americae Descriptio per I. Dankerts, Amsterdam. [ca. 1680]. Disponível em: <http://tinyurl.com/na526f3>. Acesso em: 14 de maio de 2014; Idem, Amerique Meridionale par N. Sanson d'Abbeville, Geographe du Roy, Paris, chez I'Autheur et chez Pierre Mariette, 1650. Disponível em: <http://tinyurl.com/nadxqcc>. Acesso em: 14 de maio de 2014 e Nicolas Sanson, South America Divided into its Principall Parts where are distinguished the severall States which belong to the Spanish, English, Portugals, and French, London, 1680. Disponivel em: <http://tinyurl.com/prr5byw>. Acesso em: 14 de maio de 2014.

${ }^{31} \mathrm{~A}$ imagem da montanha de prata, com a cruz no topo, pode ser lida como um símbolo da graça obtida pelos espanhóis, que começaram a explorar as minas em 1545. Os cronistas afirmam que ela se manteve fora do conhecimento dos indígenas, porque Deus estaria reservando a prata aos espanhóis, "para el alivio, para el bien, para el lucimiento y para la felicidad universal" ("para o alívio, para o bem, para o esplendor e para a felicidade universal"), como escreveu o mais importante cronista da vila de Potosi, Bartolomé Arzáns de Orsúa y Vela. Historia de la Villa Imperial de Potosí. Edición de Lewis Hanke y Gunnar Mendoza. Providence, Brown University Press, 1965, 3v. Libro II, Cap. I. En que se refiere el Descubrimiento del rico Cerro de Potosí, p. 33.
} 


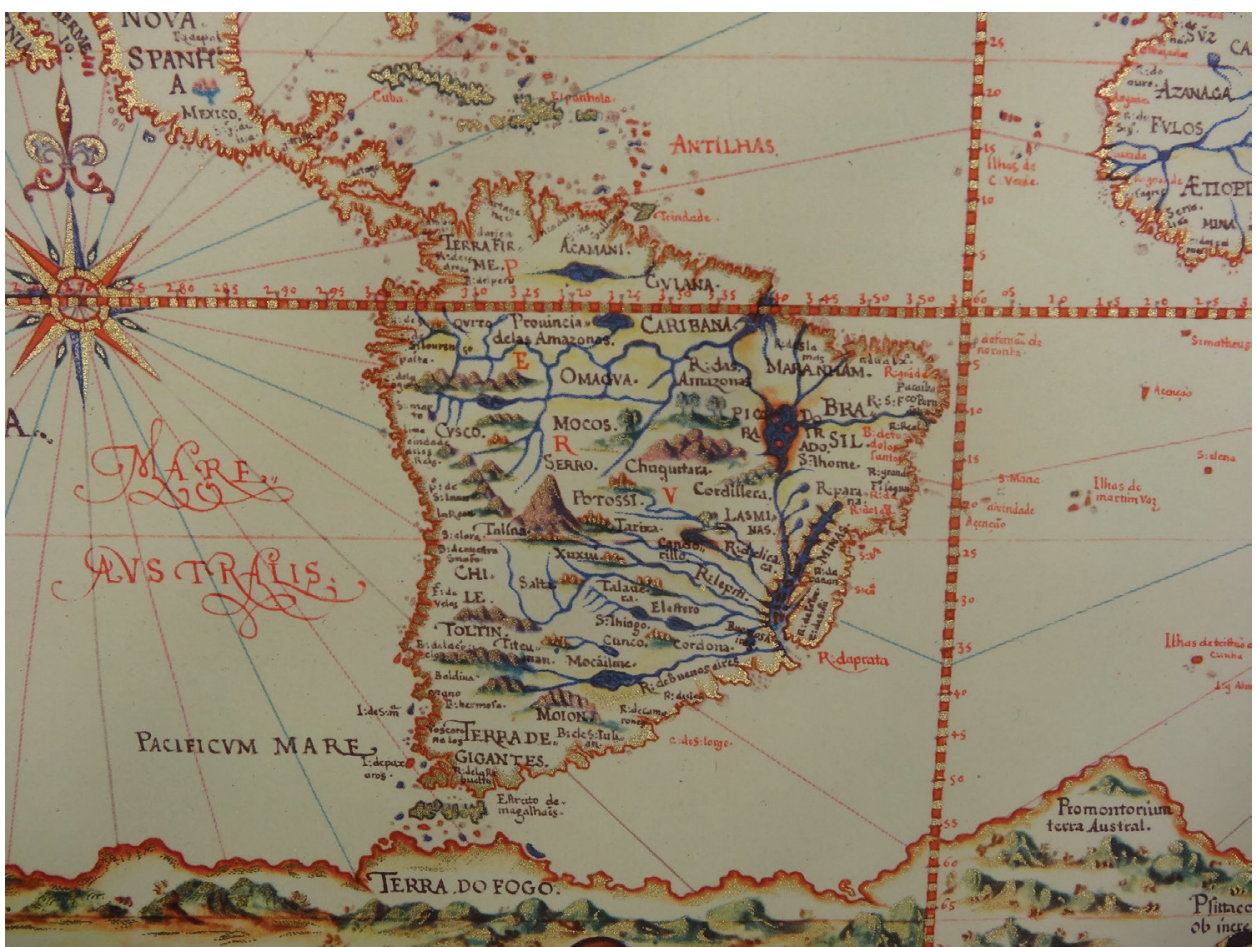

Mapa 3. Anônimo - João Baptista Lavanha e Luís Teixeira. Atlas-cosmografia, 1597 e 1612. Biblioteca Reale, Torino (detalhe).

de 1612, 1632 e 1640), seu neto, João Teixeira Albernaz II (1665 e 1667), Antonio Sanches (1618, 1623, 1637 e 1641), Pascoal Roiz (1632) e José Miranda (1688).

Uma das interpretações para essa forma de representação seria considerá-la uma estratégia adotada pelos cartógrafos, então súditos da Coroa espanhola, para utilizar como ponto de referência a fonte de riqueza mais cara ao monarca. Não havia, então, nada muito atraente a ser referenciado sobre as terras do Brasil. Elas ocupam um lugar bastante marginal nas descrições do continente, terra de canibais, produtora de pau-brasil e de aves de penas coloridas. No Livro que dá razão do Estado do Brasil, de 1612, um relatório das capitanias do Brasil encomendado por Filipe III, o capitão Diogo Campos Moreno, seu autor, apresenta o Brasil da seguinte forma: "O Estado do Brasil, Províncias de Santa Cruz, é a parte oriental do Peru povoada na costa do mar Etiópico [...]". O mapa geral que integra o livro, de autoria de João Teixeira Albernaz I, traz a presença imponente da montanha do Cerro Rico de Potosi e a cordilheira onde se encontra a montanha de prata, que atravessa o continente margeando o rio Amazonas, sugerindo, assim, uma ligação entre o Vice-reino do Peru e as Terras do Brasil. ${ }^{32}$

${ }^{32}$ A citação está em Diogo de Campos Moreno [1612], Livro que dá razão do Estado do Brasil - 1612. Edição crítica, com introdução e notas de Helio Vianna, Recife, Arquivo Público Estadual, 1955, p. 107. O mapa está reproduzido na PMC, vol. 4, Estampa 446. Sobre o Livro que dá razão do Estado do Brasil e a cartografia sobre o Brasil no período filipino, ver Andréa Doré, "O deslocamento de interesses da Índia para o Brasil durante a União Ibérica: mapas e relatos", Colonial Latin American Review, Vol. 23, Issue O2, 2014, p. 172-197. 
De forma paradoxal, no entanto, o poder português sobre o continente permanece intocável em muitos desses mapas. O brasão da dinastia dos Avis continua sendo representado na parte oriental do Novo Mundo, como já se via nos mapas de Bartolomeu Lasso, apesar de os Habsburgos exercerem a soberania sobre Portugal até 1640 e, entre 1630 e 1654, os holandeses dominarem parte do nordeste do Brasil.

Outra interpretação não invalida a primeira, mas acentua aspectos diferentes. A tradição dos mapas portugueses seria resultado das esperanças que a mina de Potosi gerou entre os portugueses de que também seriam encontradas ricas jazidas no Brasil. Uma esperança muito prática. Os portugueses, ao representarem Potosi, teriam escolhido a materialidade do que servia de base para as elaborações dos humanistas holandeses. Seria mais uma manifestação "da curiosidade relativamente temperada, sujeita, em geral, à inspiração prosaicamente utilitária", que Sergio Buarque de Holanda identificou nos cronistas portugueses dos primeiros séculos. Ao ver a crueza da montanha de Potosi nesses mapas, poderíamos reproduzir a pergunta que esse autor propõe ao aproximar os portugueses de pessoas para quem "o viver quotidiano nem os deixa oprimidos, nem os desata dos cuidados terrenos, e o freio que parece moderar sua fantasia é uma esperança contente e sossegada". Não estaria, então, também nesses mapas, "o realismo comumente desencantado, voltado sobretudo para o particular e o concreto [...]" ?33

\section{Piratas e mapas}

Além da produção cartográfica propriamente portuguesa, apenas em outro mapa encontrei a montanha de Potosi sendo representada dessa forma. A relação que proponho entre esses mapas acentua, de um lado, a importância do Peru como ponto de referência e de atração para a exploração do Pacífico. De outro lado, indica a circulação da cartografia portuguesa, mesmo tendo permanecido manuscrita na sua maior parte. Trata-se de um dos mapas do atlas de William Hack, realizado em 1683.

O Atlas Hack tem sua origem em uma expedição de corsários ingleses à costa do Pacífico ocorrida entre 1680 e 1682. Bartholomew Sharp era o líder dos corsários e foi o primeiro capitão inglês a fazer a travessia da América para a Europa, circundando o continente americano pelo sul, de oeste para leste, passando pelo Cabo Horn. Esses corsários, em 1682, capturaram na costa do Pacífico, entre o Panamá e o Equador, a nau espanhola Santa Trinidad, de 400 toneladas, e circularam pelos portos do Oceanus Peruvianus por 18 meses.

Há vários relatos conhecidos, produzidos por integrantes dessa expedição. Um relato foi entregue ao rei da Inglaterra, Carlos II, apresentado por Sharp e intitulado The Wagoner of the Great South Sea, contendo também o

33Ver Sérgio Buarque de Holanda, Visão do paraíso: os motivos edênicos no descobrimento e colonização do Brasil, 6. ed., São Paulo, Brasiliense, 1996, p. 5. Nesse livro, o autor discute diferentes manifestações da influência exercida pelas minas do Peru sobre portugueses e espanhóis no capítulo "Um outro Peru". 
atlas produzido por Hack. ${ }^{34}$ Com essa obra, cujo texto é de autoria de Basil Ringrose, integrante da viagem corsária, Sharp obteve sua liberdade ao retornar à Inglaterra, quando, junto com outros dois membros da tripulação, foi acusado pelo governo espanhol de pirataria e assassinato. Desde 1670, pelo Tratado de Madrid, quando a Espanha transferiu a possessão da Jamaica aos ingleses, os dois países estavam em paz. O tratado, no entanto, não conseguiu suspender as atividades dos piratas ingleses. Para ser inocentado pelas autoridades inglesas, Sharp ofereceu ao rei o que tinha obtido de mais precioso em sua aventura. Com a captura do navio espanhol, conseguiu um conjunto de manuscritos oficiais de direções náuticas, ilustradas por um grande número de mapas da costa e, provavelmente, um mapa geral, muito mais detalhado do que os anteriores disponíveis na Inglaterra. Sharp deu o material para ser traduzido por William Hack, negociante e copiador de mapas, e pôde oferecer às autoridades inglesas informações mais precisas sobre as rotas e portos espanhóis na América. O rei Carlos II recebeu várias cópias e outras foram encomendadas. Ao menos 13 atlas sobreviveram, preservados em instituições públicas e acervos particulares. O manuscrito autógrafo de Ringrose só foi impresso no século XX.

Três relatos publicados nos anos seguintes popularizaram a aventura de Sharp e seus homens. The Voyages and Adventures of Capt. Barth. Sharp and others, in the South Sea foi publicado em 1684 por Philip Ayres, tradutor de muitos textos de viagem. Segundo Edward Lynam, no entanto, o relato não é de Sharp, mas de John Cox, outro corsário também presente na expedição e que teve uma querela com Sharp..$^{35}$

No ano seguinte, saiu a tradução inglesa de Bucaniers of America, organizada pelo escritor e pirata, provavelmente de origem francesa, Alexandre Olivier Exquemelin, publicado em três partes datadas de 1684, contendo uma quarta parte, datada de 1685, com um texto baseado no relato de Ringrose, mas com alterações e cortes. ${ }^{36}$ E, em 1699, o próprio William Hack publicou A Collection

\footnotetext{
34"Wagoner" é uma descrição das direções de navegação e poderia ser traduzido como "roteiro" ou "derrotero". O termo "wagoner" é uma corrupção em inglês do nome de Lucas Janszoon Waghenaer, cartógrafo holandês que, em 1584, publicou o primeiro atlas marítimo com mapas e direções de navegação. Geralmente conhecido como o Spigel der Zeevaerdt, foi traduzido para o inglês quatro anos depois como The Mariners Mirrour. Tais livros foram conhecidos na Inglaterra pelo termo genérico de "waggoner", até o século XVIII. Ver Derek Howse; Norman J.W. Thrower (eds.), A Buccaneer's Atlas. Basil Ringrose's South Sea Waggoner: a sea atlas and sailing directions of the Pacific coast of the Americas, 1682, Berkeley, University of California Press, c. 1992, p. 1.

${ }^{35}$ The voyages and adventures of Capt. Barth. Sharp and others, in the South Sea: being a Journal of the same. Also Capt. Van Horn with his Buccanieres surprizing of la Vera Cruz. To which is added The true Relation of Sir Henry Morgan his Expedition against the Spaniards in the West-Indies, and his taking Panama. Published by Philip Ayres Esq., London, Printed by B.W. for R. H. and S.T. and are go be fold by Walter Davis in Amen Corner, 1684. Sobre os diferentes relatos dessa expedição, ver Edward Lynam, "William Hack and the South Sea Buccaneers", In: __. The Mapmaker's Art. Essays on the History of Maps, London, The Batchworth Press, 1953, p. 101-116 e Lawrence C. Wroth, William Hack's manuscript atlases of "The great South Sea of America", Providence, John Carter Brown Library, 1966.

${ }^{36}$ Alexandre Olivier Exquemelin, Bucaniers of America. The Second volume. Containing The Dangerous Voyage and Bold Attempts of Captain Bartholomew Sharp, and others; performed upon the Coasts of the South Sea, for the space of two years, etc. From the Original Journal of the said Voyage. Written by Mr. Basil Ringrose, Gent. Who was all along present at those Transactions, London, Printed for William Crooke, at the Sign of the Green Dragon without Temple-bar, 1685.
} 
of Original Voyages, contendo, além de um relato do capitão Sharp, os de outros piratas em suas aventuras pela América e pelo Levante. ${ }^{37}$

Desses relatos interessa destacar alguns momentos em que a atenção dos autores se volta para as informações geográficas sobre a América do Sul, aquelas de que os piratas dispunham e as que passaram a divulgar após o tempo em que navegaram pelas costas do Pacífico. No prefácio da obra que organizou e publicou em 1684, Philip Ayres explica que as explorações do Capitão Sharp pelo Mar do Sul foram realizadas a serviço do "Imperador de Darien" e considera de grande utilidade ao leitor delimitar e descrever os domínios desse régulo, ressaltando que essa informação foi omitida pelo autor em seu texto. A Província ou Distrito de Darien "confina ao sul com o Reino de Nova Granada; a leste com o golfo de Uraba ou Darien; a oeste com o Mar do Sul; e ao norte com a Província do Panamá" ${ }^{38}$

\section{O Atlas Hack tem sua origem em uma expedição de corsários ingleses à costa do Pacífico ocorrida entre 1680 e 1682}

O relato, propriamente, se inicia em abril de 1680, com a tópica da sede de ouro a justificar as ações e a dar coragem aos homens: "O que com frequência impulsiona os homens a empreender as mais difíceis aventuras é a sagrada fome de ouro; e foi o ouro a isca que tentou um grupo de animados rapazes como nós", cerca de 300 homens, "todos Soldados da Fortuna”, a serviço do dito imperador de Darien, com quem fizeram um acordo para ajudá-lo a recuperar territórios tomados pelos espanhóis. A informação geográfica sobre a sua localização associa a situação política a dados especificamente geográficos: a região se encontra entre "os dois antigos impérios do México e do Peru, e faz a junção da América do Norte e do Sul". A capital desse império de Darien não se distanciava muito de Porto Belo, para onde os espanhóis levavam seu "Tesouro" vindo da Ciudad de los Reys, ou Lima, e embarcavam em galeões com destino à Espanha.

Depois de duas semanas de viagem, por terra ou em canoas, liderados por "nosso Imperador", o grupo chegou a Santa Maria, onde atacaram o forte esperando encontrar o carregamento de ouro em pó. A expedição tencionava parar por ali, uma vez que tinham notícia de que havia ouro suficiente "para enriquecer a nós

\footnotetext{
${ }^{37}$ William Hack, A Collection of Original Voyages: containing I. Capt. Cowley's Voyage round the Globe. II. Capt. Sharp's Journey over the Isthmus of Darien, and Expeditions into the South Seas, Written by Himself. III. Capt. Wood's voyages thro' the Streights of Magellan. IV. Mr. Roberts's Adventures among the Corsairs of the Levant. Illustrated with several Maps and Draughts, London, Published by Captain William Hack, 1699.

${ }^{38^{\prime \prime}}$ It is bounded on the South by the Kingdom of New Granada; by the Gulf of Uraba or Darien on the East; by the South Sea on the West; and on the North by the Province of Panama". The voyages and adventures of Capt. Barth. Sharp and others, in the South Sea: being a Journal of the same. Also Capt. Van Horn with his Buccanieres surprizing of la Vera Cruz. To which is added The true Relation of Sir Henry Morgan his Expedition against the Spaniards in the West-Indies, and his taking Panama. Published by Philip Ayres Esq., London, Printed by B.W. for R. H. and S.T. and are go be fold by Walter Davis in Amen Corner, 1684, Preface, fl. A3.
} 
todos". Os espanhóis, porém, haviam levado o ouro dois dias antes. No sábado, dia 17 de abril, o autor escreveu, avaliando a reação dos piratas frente à frustração de saber que não havia mais ouro para o saque: "Desapontamento é um incentivo para a vingança, e a boa resolução o comandante do Sucesso" ${ }^{39}$

Decidiram seguir para Arica, o porto pelo qual se escoava a prata do interior. Como muitos outros europeus de diferentes origens, os piratas ingleses possivelmente conheciam a fama de Potosi. Na Inglaterra, circulava a expressão "as rich as Potosi", ${ }^{40}$ um indício da reputação das minas espanholas do Peru. Segundo o relato publicado por Philip Ayres:

Este porto de Arica é situado em um vale muito agradável ladeado por um rio, e é o embarcadouro [embarcadero, em espanhol] para escoar o tesouro que vem das minas da montanha de Potosy, é um bom porto, e seguro, e está a dezoito graus e vinte minutos de latitude sul, e um ar saudável. ${ }^{41}$

Conforme descrito em Bucaniers of America, "Um velho, que tinha navegado durante muito tempo entre os Espanhois, contou que podia nos levar a um lugar chamado Arica. Até a dita cidade, ele disse, toda a prata era levada de Potosi, Chuquiasaca, e vários outros lugares do interior, onde era extraída das Montanhas e Minas".42 Ringrose também trata das minas de Potosi quando chegam ao porto de Arica, onde os corsários estiveram entre 30 e 31 de janeiro de 1681: "Aqui há delicados frutos e eu caminhei uma légua por um caminho de oliveiras. Aqui há uma estrada para Potosi e para Punio, onde estão ricas minas". ${ }^{3}$ O Porto de Arica é descrito como "o embarcadouro onde a prata de Potosi e outras

\footnotetext{
39 "to enrich us all"; "Disappointment is an incentive to Revenge, and good Resolution the commander of Success". The voyages and adventures of Capt. Barth. Sharp and others, in the South Sea: being a Journal of the same. Also Capt. Van Horn with his Buccanieres surprizing of la Vera Cruz. To which is added The true Relation of Sir Henry Morgan his Expedition against the Spaniards in the West-Indies, and his taking Panama. Published by Philip Ayres Esq., London, Printed by B.W. for R. H. and S.T. and are go be fold by Walter Davis in Amen Corner, 1684, p. 9.

${ }^{40}$ Ver Lewis Hanke, The Imperial city of Potosí. An unwritten chapter in the history of Spanish America, The Hague, Martinus Nijhoff, 1956, p. viii. O autor explica que Potosi como sinônimo de riqueza verifica-se no Roget's International Thesaurus of English Words and Phrases, n. 803. Ver também Matthew Smith, "Laboring to choose, choosing the labor: coercion and choice in the Potosi Mita", Past Imperfect, vol. 10, 2004, p. 31.

4i"This Arica is seated in a very pleasant Vally by a River side, and is the Barkador of place for Shipping off the Treasure which comes from the Mines of the Mountain of Potosy, is a good Harbour, and secure, and lies in eighteen deg. and twenty min. South latitude, and a Healthy Air." The voyages and adventures of Capt. Barth. Sharp and others, op cit., p. 60-61.

${ }^{42}$ "A certain old man, who had long time sailed among the Spaniards, told us, he could carry us to a place called Arica. Unto which town, he said, all the Plate was brought down from Potosi, Chuquiasaca, and several other places within the Land, where it was digged out of the Mountains and Mines", apud Derek Howse; Norman J.W. Thrower (eds.), A Buccaneer's Atlas. Basil Ringrose's South Sea Waggoner: a sea atlas and sailing directions of the Pacific coast of the Americas, 1682, Berkeley, University of California Press, c. 1992, p. 13. Essa obra traz pela primeira vez a edição do waggoner de Ringrose e também reproduz o texto contido na edição de Exquemelin, Bucaniers of America.

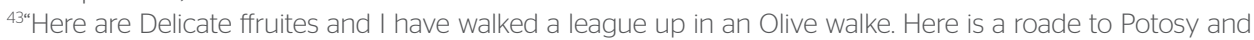
to Punio, where are rich mines". Derek Howse; Norman J.W. Thrower (eds.), op cit., p. 214. Potosi está a 560 milhas, ou $900 \mathrm{~km}$ pela estrada de Arica na costa, atinge-se pelo caminho de Puno na margem oeste do Lago Titicaca.
} 


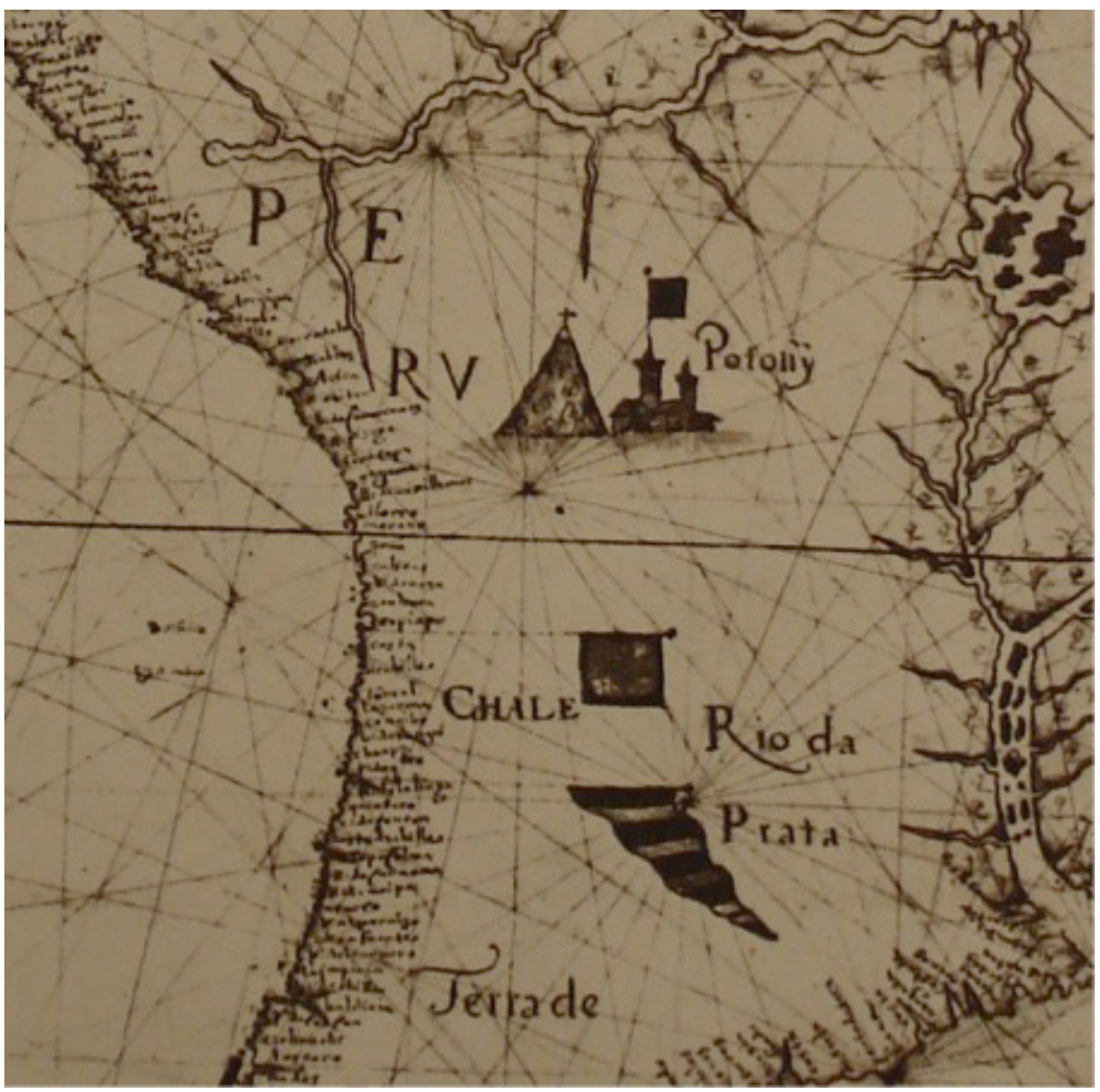

Mapa 4. João Teixeira Albernaz II, 1667 (detalhe)

minas embarcam para Lima", sendo informada a sua localização: "Este porto está a $18^{\circ} 36^{\prime}$ de latitude Sul" ${ }^{44}$

O primeiro mapa do Atlas Hack, que reúne cópia dos mapas tomados da nau espanhola, contém a costa ocidental do continente e a representação da montanha de Potosi muito semelhante à imagem utilizada pelos cartógrafos portugueses. A comparação entre a produção de João Teixeira Albernaz II (Mapa 4) e de duas versões manuscritas do Atlas Hack, uma preservada no National Maritime Museum (Mapa 5), de Londres, e outra na John Carter Brown Library, em Providence, nos Estados Unidos (Mapa 6), permite supor que alguma forma de circulação dessa imagem aconteceu. Ou a tripulação corsária de Bartholomew Sharp teve acesso a exemplares da cartografia portuguesa, ou

\footnotetext{
44"the embarquadero where the silver of Potosy and other mines embarque for Lima"; "This port is in South Latt. 18³6". Derek Howse; Norman J.W. Thrower (eds.), A Buccaneer's Atlas. Basil Ringrose's South Sea Waggoner: a sea atlas and sailing directions of the Pacific coast of the Americas, 1682, Berkeley, University of California Press, c. 1992, p. 214; 216. Note-se a pequena diferença em relação à informação contida no outro relato, em que Arica está a $18^{\circ} 20^{\prime}$ de Latitude Sul.
} 


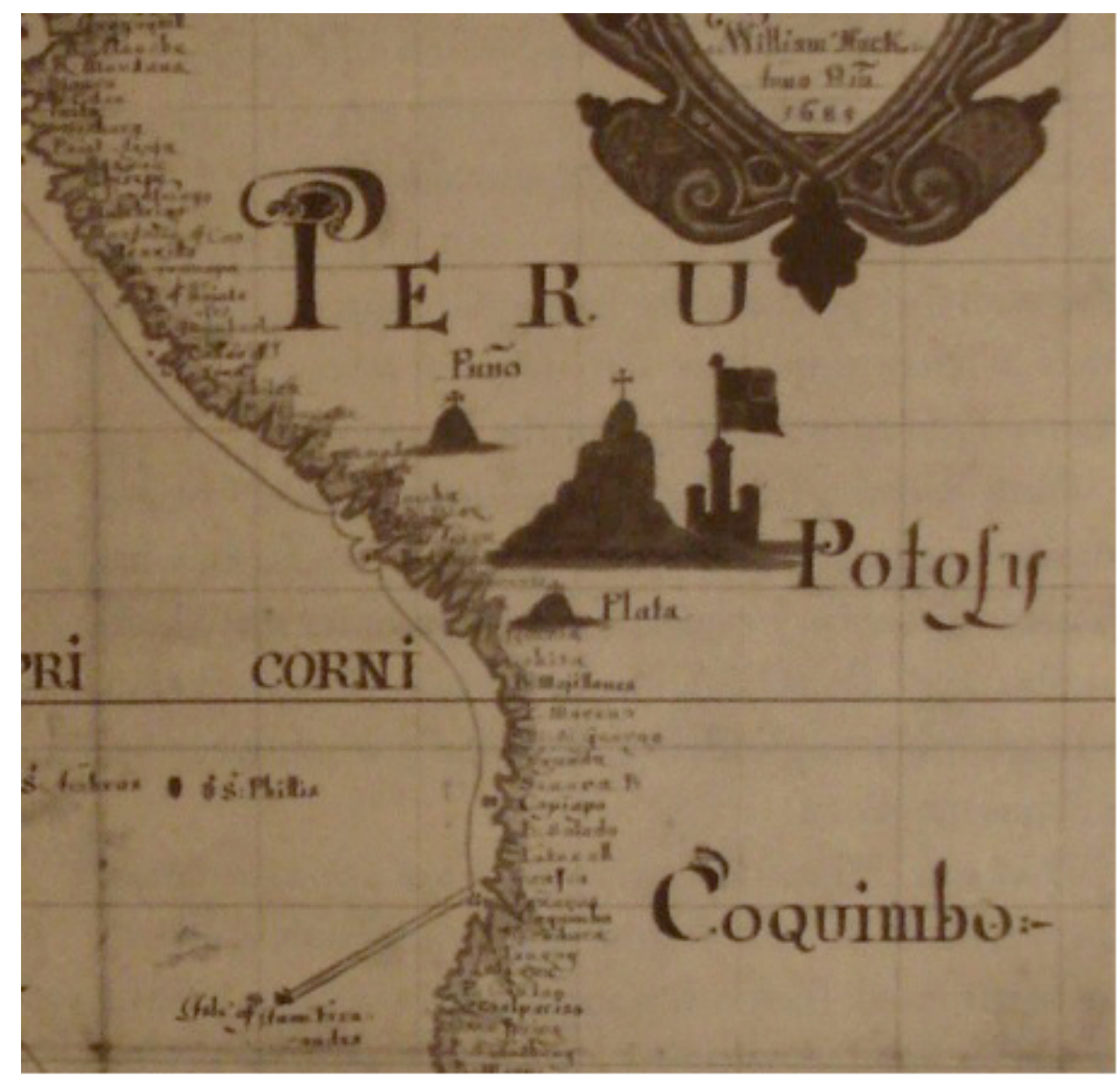

Mapa 5. Atlas Hack, National Maritime Museum (detalhe).

essa circulação antecedeu a captura da nau pelos piratas e os próprios mapas apreendidos teriam influência da cartografia portuguesa. ${ }^{45}$

Essas diferentes formas de representação abrem espaço para várias conclusões. A análise da cartografia permitiu identificar o oscilante entendimento que os europeus possuíam sobre o Novo Mundo. O conjunto de mapas citados não contempla a produção do século XVIII, mas sabemos que foi ao longo desse século, impulsionado em grande medida pela descoberta de ouro nas regiões centrais do Brasil e pelas disputas de fronteira entre Espanha e Portugal, que o conhecimento sobre o interior do continente se intensificou. Da mesma forma, nos séculos XVI e XVII, a busca de metais havia estimulado as explorações e com elas as descrições geográficas contidas nos mapas e cosmografias. Na construção desse entendimento, não

${ }^{45} \mathrm{Cf}$. Derek Howse; Norman J.W. Thrower (eds.), A Buccaneer's Atlas. Basil Ringrose's South Sea Waggoner: a sea atlas and sailing directions of the Pacific coast of the Americas, 1682, Berkeley, University of California Press, c. 1992. A obra contém uma reprodução do mapa da costa pertencente ao manuscrito do National Maritime Museum, de Londres. O outro manuscrito citado está na JCBL, em Providence, Estados Unidos. 


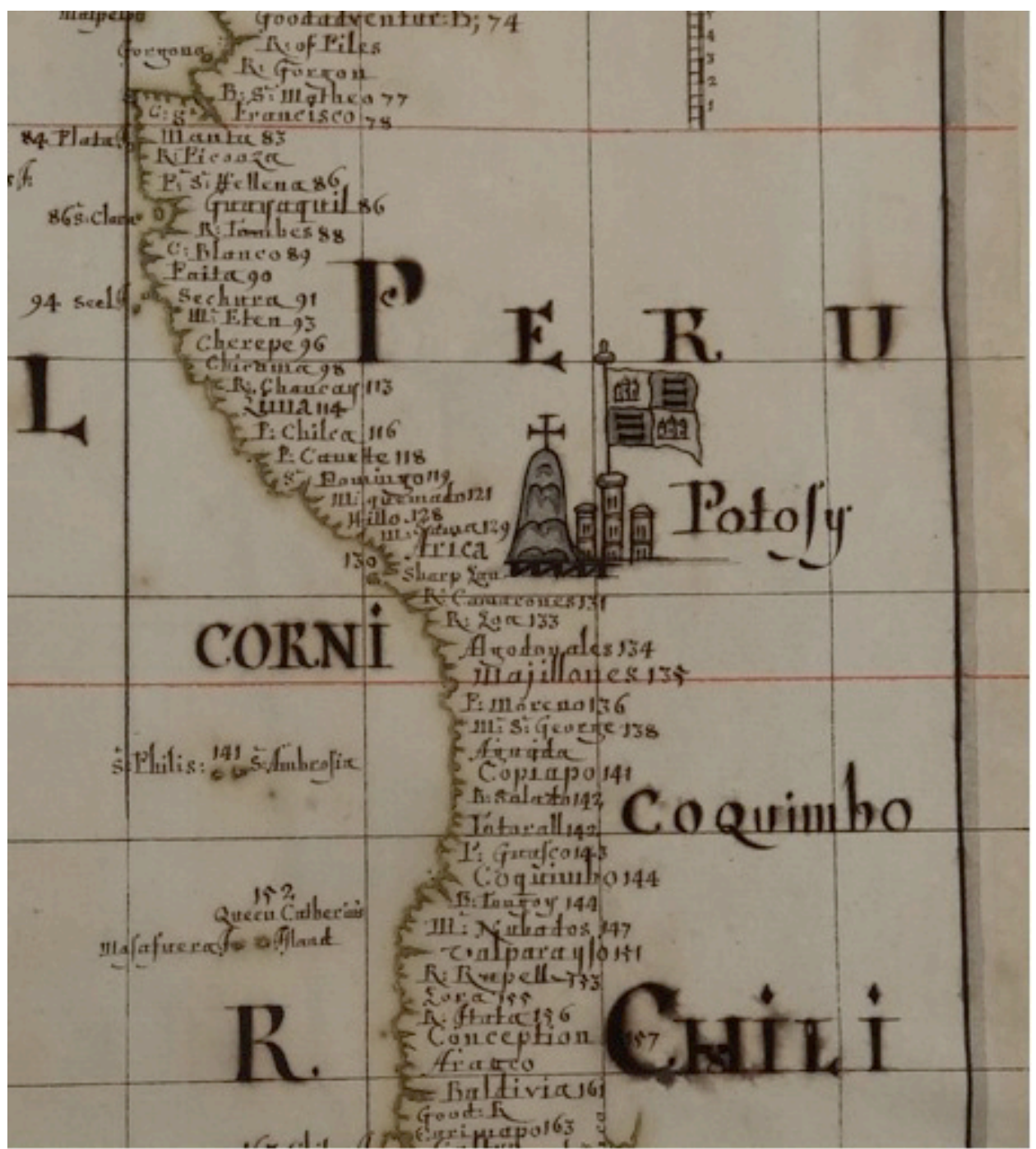

Mapa 6. Atlas Hack, John Carter Brown Library, Providence (detalhe).

cabe falar de um processo linear em direção à precisão e acurácia, mas de ambivalências e da coexistência de diferentes representações do espaço.

O uso de diferentes nomenclaturas para o continente e o oceano que o envolve obedeceu a diversas ordens de interesses e, como se analisou neste artigo, a um conjunto variável de projeções de expectativas, por parte tanto dos países ibéricos, diretamente envolvidos na conquista, quanto de piratas e de humanistas seduzidos pelo desafio de "mapear" um novo continente. As notícias que se produziram e veicularam sobre o Peru e suas riquezas pautaram a hierarquia dos espaços da América do Sul, acompanhando as oportunidades de exploração e as empreitadas, bem sucedidas ou não. Essas conclusões se aliam à historiografia recente de que a imagem da América como uma entidade geográfica única - que poderia também ter 
sido edificada sob o nome Peruana - foi o resultado de uma "construção mental ativa", na expressão de Zerubavel. ${ }^{46}$ As evidências aqui discutidas mostram que o nome do continente, assim como a concepção da sua unidade, resultou de uma construção europeia de longa duração, superando tanto a heterogeneidade local quanto a multiplicidade de esperanças lançadas sobre suas terras ao longo de, ao menos, dois séculos.

${ }^{46}$ Ver Eviatar Zerubavel, Terra Cognita. The mental Discovery of America, New Brunswick, Rutgers University Press, 1992, p. 40. A mesma preocupação em identificar os contornos de uma imagem unificada, desta vez identitária, do continente está presente em Felipe Fernandez-Armesto, The Americas. A Hemispheric Historic, New York, Modern Library Edition, 2003. Sobre a paulatina construção da imagem da América como um só continente, ver também Seymour I. Schwartz, The Mismapping of America, Rochester, The University of Rochester Press, 2003; Idem, Putting "America" on the map, New York, Prometheus Books, 2009; Susan Schulten, The Geographical Imagination in America, 1880-1950, Chicago; London, The Chicago University Presss, 2001. 